\title{
“NA TORPEZA NAUSEANTE HAVIA MUITA COISA PURA": DESPERSONALIZAÇÃO E AFIRMAÇÃO DO SUJEITO EM MEMÓRIAS DO CÁRCERE E NAS RECORDAÇÕES DA CASA DOS MORTOS
}

\begin{abstract}
Ana Carolina Huguenin ${ }^{1}$
Resumo: A "torpeza" e a "pureza" que dão título a este texto são observadas por Graciliano Ramos no presídio da Ilha Grande. Lançado num ambiente hostil e desconhecido, o autor registra o processo de negação dos direitos e da dignidade dos presidiários, descritos através de expressões como "rebanho" e "fantasmas". A convivência com prisioneiros originários contextos sociais e culturais em ampla medida desconhecidos abre caminho ao estranhamento, mas também a aproximações. Em Memórias da casa dos mortos, Dostoiévski se encontra em posição semelhante, e registra, com grande ênfase, a "pureza" em meio à "torpeza", a afirmação da vida e da personalidade entre os "mortos" recolhidos na "casa" siberiana. O presente artigo tem como objetivo estabelecer comparações e aproximações entre as memórias carcerárias de ambos os literatos, a partir da problemática da negação da dignidade humana, e, por outro lado, da resistência dos presidiários, que lutam para afirmar suas vidas e personalidades, diante de circunstâncias restritivas e brutais.
\end{abstract}

Palavras-chave: Graciliano Ramos; Dostoiévski; Memória carcerária.

Abstract: Villainy and purity are noticed by Graciliano Ramos in prison. Thrown in to an unknown, hostile and dehumanizing environment, the author registered in his memoires the systematic denial of prisoner's rights and dignity. In their misery, the incarcerated are described as "cattle" or "ghosts". Cohabiting with common criminals, from completely different social and cultural backgrounds, Graciliano Ramos experienced estrangement but also new encounters. In The House of the Dead Dostoevsky finds himself in a similar position, noticing and registering "purity" mixed with "villainy" among the incarcerated in Siberia, who fight to preserve their lives and affirm their personalities. This paper establishes a comparison between the two author's prison memoires. Both of which discuss the question of denial of human dignity on one hand, and on the other hand prisoner's resistance and struggle to live and to affirm their humanity in brutal and restrictive circumstances.

Keywords: Graciliano Ramos, Dostoevsky, Prison Memoires.

1 Doutora em História pela UFF. Professora de História Contemporânea na UERJ, onde também atua como coordenadora da unidade Museu do Cárcere, no Ecomuseu da Ilha Grande.

Literatura e Autoritarismo, Santa Maria, n. 31: A experiência do confinamento, jan.-jun. 2018, p. 35-44. - ISSN 1679-849X 
A bordo do porão do navio Manaus - na "cova movediça" (RAMOS, 2015, p.135) Graciliano Ramos realizou a travessia entre Recife e Rio de Janeiro. Lá seria mantido junto a outros presos políticos na Casa de Detenção do Distrito Federal até a transferência, em junho de 1936, para a Colônia Correcional de Dois Rios (CCDR), localizada em Ilha Grande. Espremidos no subsolo da embarcação, centenas de corpos, alguns dos quais recém-torturados, se amontoavam anônimos, oprimidos e semi-sufocados entre dejetos humanos, restos de comida, e na incerteza quanto ao seu destino. Morte e fantasmagoria perpassam a descrição do autor: "estávamos ali mortos, em decomposição, e era razoável (para os passageiros de primeira classe] evitarem o contágio" (RAMOS, 2015, p.117). Ou ainda: "punha-me a tossir [...] sufocado [...] levantava os braços e quase alcançava o teto baixo, a tampa de nossa catacumba". (RAMOS, 2015, p. 109.) No interior da "catacumba" flutuante, escondiam-se os "mortos": "éramos fantasmas, rolaríamos de cárcere em cárcere, findaríamos num campo de concentração" (RAMOS, 2015, pp. 160-1). Subtraídas e negadas a liberdade e todas as formas de dignidade, com as vidas subitamente interrompidas e para sempre marcadas pela experiência prisional, a condição dos encarcerados é identificada a uma condição mortal, a não vida, ou à própria negação do que os constitui e identifica enquanto seres humanos. As memórias da descida ao porão relacionam a alienação radical em relação ao convívio social com a decrepitude e o silêncio do túmulo.

Após o embarque no Rio de Janeiro e, decorridos alguns meses, a transferência para a Ilha Grande, Graciliano se encontraria novamente em circunstâncias de isolamento, humilhação e perigo - "era um sujeito morto" (RAMOS, 2015, p. 404), afirma o memorialista, a bordo do porão de outra embarcação que, desta vez, o levaria à prisão que se notabilizou pelo epíteto infame de "caldeirão do diabo".

As memórias de uma experiência prisional associada à suspensão da vida marcam o próprio título do relato de Dostoievski. Os "mortos" da "casa" siberiana, condenados a trabalhados forçados sob escolta armada, sob o peso e o estigma dos grilhões, eram os "infelizes" - como o povo russo os chamava (DOSTOIÉVSKI, 2003, p. 94) - da fortaleza militar de Omsk, despojados dos direitos civis e submetidos a castigos corporais de tal severidade que por vezes os transfigurava, no sentido próprio e literal do termo, em homens mortos. ${ }^{2}$

Mas, ainda que lançados em circunstâncias restritivas e brutais, os encarcerados não abririam mão da busca pela afirmação continua, por vezes através de atos desesperados, da sua condição de sujeito, manifestando personalidades e desejos, que, embora soterrados na "casa dos mortos", permaneceriam teimosamente vivos. Afinal, "não se pode transformar uma pessoa viva num cadáver: ela permanecerá com seus sentimentos, com desejos de vingança e vida, com paixões e necessidades de saciá-las.” (DOSTOIÉVSKI, 2003, p. 93). Essa verdade se expressa de maneira particularmente clara quando a "casa" se abre ao mundo exterior, convidando-o, com orgulho, a assistir ao espetáculo teatral protagonizado pelos prisioneiros. Dostoiévski se impressionara com a força dramática e cômica das interpretações dos detentos, com a música vivaz, o cenário e os figurinos improvisados, e com as can-

2 Em russo, o título da obra é Zapiski iz Miortovovo Doma (Записки из Мертвого дома) - о que pode ser traduzido, de forma literal, por "Anotações da Casa Morta". No título original, portanto, a morte é associada diretamente ao presídio, ao local de encarceramento, e não aos sujeitos encarcerados. De toda forma, o título não deixa de relacionar a experiência prisional à suspensão da vida, conforme afirmado no presente texto. 
ções e instrumentos populares - balalaicas, rabecas, violões e pandeiros - que compunham a orquestra do teatro. (DOSTOIÉVSKI, 2003). Os “infelizes" cantam e dançam, vibrando continuamente nas Recordações, enquanto reivindicam o status pleno de seres humanos. Se no "túmulo flutuante" navegado por Graciliano um samba, cantado a plenos pulmões pelos prisioneiros, rompe o isolamento e a mortificação dos navegantes do subsolo, afirmando sua condição de seres humanos perante si mesmos, perante as autoridades e os passageiros da primeira classe (RAMOS, 2015), na "Casa dos mortos", a música, a dança e a atuação dos condenados, recriadas pelo autor no capítulo "O espetáculo", cumprem função semelhante.

Em suas experiências carcerárias, ambos os romancistas se viram cercados de pessoas com as quais jamais haviam convivido fora da prisão: os chamados criminosos "comuns", oriundos de contextos sociais e culturais em ampla medida desconhecidos, distantes da vivência dos autores e de seus pares. A distância entre prisioneiros "políticos", em sua maioria advindos de camadas mais instruídas e abastadas, e presos "comuns" abre espaço ao isolamento e ao estranhamento, mas também a aproximações e à complexificação de noções que os memorialistas carregaram consigo para o cárcere.

Sobre a convivência com pessoas de outras origens, Graciliano observa, ainda a bordo do navio Manaus:

Lá fora [...] usávamos linguagens diferentes e nos distinguíamos pela roupa. Ali [...] meio nus [...] nos íamos depressa nivelando. [...] Operários e militares sediciosos, pequeno-burgueses detidos por suspeita, socialmente valíamos tanto como o ladrão que me vendera a rede. [...] Pela primeira vez pessoas de outra classe se manifestavam com franqueza diante de mim. Certas discrepâncias faziam-me pensar em nossas vidas anteriores: um vosmicê me chocava [...]. Não havia à beira do lago nauseabundo espaço para nenhum senhor (RAMOS, 2015, p. 139).

No presídio de Omsk, os condenados de origem camponesa - ladrões, assassinos e contrabandistas - se manifestariam também com inédita franqueza diante de Dostoiévski. Tal franqueza, porém, não deixava de lado o pronome (e a condição do) “senhor", nobre letrado - antes marcando, a todo o momento, a diferenciação social, através de manifestações abertas, jamais presenciadas fora daquela "Casa", de desconfiança, desafio e hostilidade. A convivência de Graciliano com presos "de outra classe", por sua vez, não fora tão prolongada. Após desembarcar do Manaus, o escritor foi transferido para a Casa de Detenção do Rio de Janeiro e mantido junto a outros prisioneiros acusados de envolvimento no Levante de 1935, entre os quais Olga Benário, Nise da Silveira e Agildo Barata. Tratavam-se, em grande parte, de funcionários públicos, intelectuais, oficiais e profissionais liberais, pessoas cujas origens, vivência e visão de mundo não diferiam radicalmente das do escritor. Entre os companheiros de prisão do Rio de Janeiro, havia também "pessoas de outras classes", mas sempre prisioneiros "políticos". Algo muito diverso o esperaria na Ilha Grande, e a perspectiva da transferência, que fatalmente viria, enchia o memorialista de horror e indignação: 
Por que [...] me mandavam para aquele inferno? [...] Burrice misturar com vagabundos e malandros a um sujeito razoável [...] absolutamente alheio a essas criaturas. Tencionavam corrigir-me na Colônia [...] onde guardam a canalha, o enxurro, vidas sórdidas. (RAMOS, 2015, pp. 364-365)

"Aquele inferno" (como se expressa Graciliano), i.e. a Colônia Correcional de Dois Rios, surgira em 1894, nas próprias origens da experiência republicana, em meio a um projeto de modernização excludente que na década seguinte "botou abaixo" os rastros do passado colonial, no esforço violento de erigir a "Paris dos trópicos". O inferno insular era reservado, de início, justamente a "vagabundos e malandros" (pequenos contraventores criminalizados pelo Código Penal de 1890 - mendigos e ébrios, além de prostitutas, "vadios", menores infratores e capoeiras): "vidas sórdidas" (ainda de acordo com as palavras do memorialista) a serem deportadas, retiradas das vistas dos "sujeitos razoáveis" da capital civilizatória, os quais permaneceriam, de resto, "alheios a essas criaturas". Nos anos 1930, a Colônia passou a receber quantidade crescente e substancial de prisioneiros políticos. Ao final de 1936, ano em que o escritor lá esteve preso, às vésperas do Estado Novo e sob a forte repressão comandada pelo chefe de polícia Filinto Muller, o total de detentos chegou a 1.388, mais que quadruplicando em relação ao ano anterior, segundo dados levantados por M. Sepúlveda dos Santos (2009). Graciliano descreve enquanto "curral de arame" (RAMOS, 2015, p. 380) o pátio de areia molhada, cercado de arame farpado, onde ficavam presidiários famintos e exaustos em decorrência de trabalhos forçados, infestados de parasitas e doenças, oprimidos pela humilhação, desumanizados como "bonecos" (RAMOS, 2015, p. 414); "bichos miúdos" (RAMOS, 2015,p. 420); "frangalhos, fontes secas, egoísmos cheios de pavor" (RAMOS, 2015, p. 426); "tropel de bichos mansos na areia molhada" (RAMOS, 2015, p. 436).

A distância e o estranhamento em relação aos presos comuns, de início, permanecem imensas. Antes de ser enviado à Colônia, ainda na Casa de Detenção, Graciliano ouvira o horripilante relato de Francisco Chermont (filho de Abel Chermont, senador preso em 1936) que regressara perturbado e maltrapilho da Ilha Grande. Sobre os episódios de violência extrema, o romancista pondera:

No porão do Manaus, tinham-me visto na companhia de pessoas aviltadas [...]. No entanto, conseguira habituar-me. [...]. O porão do Campos [que conduzia os presos à Ilha Grande] era muito diverso. Justapunham-se ali duas sociedades inconciliáveis: uma afeita às ideias e aos costumes regulares [...]. Outra [...] dirigindo-se por [...] regras absurdas. A primeira, centena e meia de políticos [...]; a segunda, quatrocentos ou quinhentos malandros [...], refugo tumultuoso, fervilhava [...] naquele esgoto social como um formigueiro assanhado. (RAMOS, 2015, pp. 313-314)

Logo após o ingresso no "curral", a noção de apartamento irreconciliável em relação à "outra" sociedade, ou ao "esgoto social" permanece, escorada na desconfiança e na ausência de identificação: "nivelava-me a ladrões, vagabundos, malandros [...]" (RAMOS, 2015, 
p. 449). Ou ainda: Que me importavam as figuras tristes consumidas no curral de arame? Preferível não conhecê-las. Pra quê? Tinha-me arrastado mais de quarenta anos longe deles, sem cogitar da existência deles, e surgia-me de chofre a necessidade besta de uma aproximação inútil [...] (RAMOS, 2015,pp. 381-382).

Uma aproximação significativa, no entanto, estava a caminho, para feliz espanto do memorialista, que não só travaria conhecimento e desenvolveria intimidade, mas descobriria, entre certas "figuras tristes", algo infinitamente mais complexo e humanizado que a imagem indistinta de um "formigueiro assanhado" e brutal. Da imagem abstrata, generalizante e distanciada dos - assim ditos - "vagabundos e malandros" surgiriam feições, nomes próprios e apelidos, vozes e atitudes familiares, cúmplices na tragédia e no abandono.

Quando o escritor adentra pela primeira vez o refeitório da Colônia, um cheiro nauseabundo de carniça e podridão o leva a imaginar que um animal estaria a se decompor nas proximidades. A perspectiva de ingestão do alimento de aspecto e odor repugnantes suscita recusa, que não permaneceria indiferente a um estranho que se ocupava de servir os companheiros de prisão: "da figura indistinta veio um conselho doce e lento: - "Coma. [...]. A comida [...] foi preparada para os senhores.[...]." (RAMOS, 2015, p.418). Diante de recusa obstinada, a doçura do conselho também se obstina, e a primeira reação do memorialista reitera a desconfiança e o estranhamento suscitados pelo novo ambiente prisional: "Nunca imaginara que um homem se dirigisse a outro daquele jeito: desvelo excessivo, uma ternura flácida e trêmula. [...]. De fato conhecia a bondade esquisita, mas era preferível não receber. [...]. E achava-me ingrato." (RAMOS, 2015, p. 419)

Tratava-se o prisioneiro de um homossexual. A bondade - atributo universal - vinha de um homem cuja orientação sexual o autor tendia a considerar "esquisita", desviante. "Não me ocorrera a existência de coração nessas anomalias; de longe, exclusivista e rígido, habituara-me a julgá-las sordidez apenas" (RAMOS, 2015, p. 467). "De longe" é a condição mesma que se coloca em jogo, sob pressão e subversão, na convivência forçada com o universo nada familiar, a ponto de abalar significativamente a "rigidez" e o "exclusivismo" anteriores, abrindo caminho a uma nova evidência: "Na verdade, era impossível transforma-me, vencer o nojo que esses desvios me causavam. [....]. Mas uma evidência entrava a impressionar-me: na torpeza mais nauseante havia uma coisa muito pura." (RAMOS, 2015, p. 468).

Admitir, enquanto evidência, "pureza" e "coração" entre pessoas até então vistas a partir do estranhamento profundo, da distância abstrata e generalizante - desumanizante - é algo que a convivência, a ruptura com a demarcação "de longe", permitira. Em meio à desumanização a que o estado de exceção reduzira o condenado, em meio ao que Giorgio Agamben (2010) denomina "vida nua" - a perda ou o desnudamento dos direitos políticos a partir da intervenção ou do exercício do poder soberano, que decide sobre, e implementa o, estado de exceção - Graciliano, reduzido ele próprio à "vida nua", animalizado no "curral de arame", irá descobrir, no cárcere, marcas complexas de humanização até então insuspeitas.

Em meio ao grupo indistinto e anônimo de prisioneiros de início referidos como "vagabundos" surgem figura próximas, a exemplo de Cubano, Paraíba e do ladrão Gaúcho. O último suscita no memorialista simpatia instantânea: "confessei a mim mesmo que poderia 
tornar-me sem esforço amigo do ladrão.” (RAMOS, 2015, p. 425). Estabelecendo improvável amizade, Graciliano ouve com interesse e gosto as peripécias e desventuras narradas pelo prisioneiro, experiente em roubar residências. Tais narrativas davam conta de um universo desconhecido, do contexto popular e urbano cariocas. A própria linguagem de Gaúcho escapa à familiaridade: são gírias absolutamente incompreensíveis ao ouvinte culto, que obrigam o narrador a interromper-se e oferecer explicações. O escritor faz perguntas e anota, demonstrando vivo interesse:

- Você sabe que tenho interesse de ouvir suas histórias?

- Sei. Vossa mercê vai me botar num livro.

- Quer que eu mude seu nome?

- Mudar? Por quê? Eu queria que saísse o meu retrato

(RAMOS, 2015 p.452).

Fábio César Alves observa que entre o ladrão e seu culto companheiro de prisão há, apesar da aproximação e do nivelamento imposto pelo contexto carcerário, uma relação assimétrica de poder econômico e simbólico:

o reconhecimento tanto da individualidade de Gaúcho quanto de seu universo, dependem, de algum modo, da vontade do prisioneiro, que é escritor. Alijado do mercado de trabalho, marginalizado pelo Estado [...] o pária imagina ter sua existência reconhecida quando o arbítrio do homem culto (e preso) se dispõe a fazê-lo, seja no lugar concreto da cadeia, seja no espaço simbólico da escritura (ALVES, 2016, p. 186).

É a linguagem culta e literária, distante das gírias populares utilizadas por Gaúcho, que irá "botar num livro", rememorando, testemunhando e divulgando, os sofrimentos e abusos que marcaram a história da CCDR. O ladrão e o escritor são co-partícipes e companheiros na experiência do horror - no contexto de uma aproximação improvável, promovida pelo Estado de exceção, no âmbito da experiência traumática e das cercas do "curral". Mas é ao escritor que caberá a testemunha e a denúncia, a palavra, o acesso ao público culto, o "retrato" literário e histórico, testemunhal; o registro da memória. Gaúcho, Paraíba, Cubano e tantos outros "malandros", próximos ou distantes de Graciliano, tinham como destino, desde as origens da experiência republicana, a "correção" e a alienação na CCDR. Eles não tinham a palavra - o status, o reconhecimento social e o alcance simbólico do homem de letras. Sem as Memórias do Cárcere seus "retratos" - necessariamente perpassados pela linguagem, a visão, o rememorar, a (re) elaboração, e, até certo ponto, o “arbítrio" do autor - não ficariam registrados, e muito provavelmente se apagariam como se nunca houvessem existido, na condição de marginalidade e invisibilidade a que estavam submetidos 
dentro - e fora - do cárcere.

Ao discutir a questão da escrita de testemunho nas Memórias, Alfredo Bosi observa:

O testemunho [...] quer-se verídico, aspira a certo grau de objetividade. Como tal, casa memória individual com história. Mas o testemunho também se sabe a obra de uma testemunha, que é sempre um foco singular de visão e elocução. Logo, [...] é subjetivo, e, por esse lado, se aparenta com a narrativa literária em primeira pessoa. [...].

As Memórias do cárcere dão o paradigma dessa complexidade textual. Ao percorrê-las, somos levados tanto a reconstituir a fisionomia e os gestos de alguns companheiros de prisão de Graciliano, quanto a contemplar a metamorfose dessa matéria em prosa una e única - a palavra no narrador (BOSI, 1995, pp. 309-310).

A palavra, portanto, é do narrador, que reconstitui e nos dá acesso à "fisionomia e aos gestos dos companheiros de prisão" - de outro modo relegados ao esquecimento e ao desaparecimento, quando se tratam, principalmente, de anônimos prisioneiros "comuns" da Colônia Correcional de Dois Rios. A palavra funciona ainda como uma espécie de filtro entre a experiência coletiva, o mundo exterior e a experiência histórica de um período autoritário e, por outro lado, a vivência individual, no exercício de rememoração e evocação do drama vivido pessoal e coletivamente. Percorrendo Recordações da Casa dos Mortos, também se perfilam diante de nós "gestos e fisionomias" marcantes, aos quais a palavra do narrador, ao resgatar da "morte" - do esquecimento e do silêncio que caracterizavam a experiência da Kátorga (sistema de trabalhos forçados extraídos dos prisioneiros sob o regime tsarista) - confere vida por meio do testemunho ou, mais precisamente, por meio da literatura testemunhal.

A obra de Dostoiévski permanece uma das mais importantes referências - documental e artística - da vida prisional na Rússia tsarista. ${ }^{3}$ Enquanto Graciliano passara apenas 18 dias entre prisioneiros "comuns", o autor da Casa dos mortos passara quatro anos (18501854) entre encarcerados de origem camponesa, cujo "retrato", mais pormenorizado e complexo, envolvendo seus crimes, dramas e comportamentos, percorreu o Império russo e o mundo, se eternizando.

Os primeiros capítulos da obra, intitulados "Primeiras Impressões", expressam grande assombro, isolamento e mal-estar diante da nova situação na qual o romancista fora lançado, e particularmente diante da hostilidade manifestada pelos presidiários "comuns", do povo - hostilidade que chega a colocar sua vida em risco. Mas, ao longo da narrativa, o memorialista revela as histórias e o grande drama humano que se escondem sob a superfície embrutecida dos presos com os quais convivera e dos quais se aproximara.

3 Segundo Joseph Frank, "As memórias de prisão têm sido tema tão familiar (e a literatura russa está agora [...] tão rica de exemplos) que tendemos a esquecer que foi Dostoiévski quem deu a primeira obra-prima desse tipo a seu país. Recordações da casa dos mortos criou o gênero na Rússia, respondendo a uma imensa e apreensiva curiosidade sobre as condições de vida daqueles 'infelizes"'. (Frank, 2002, p. 302). 
O capítulo "Festa do Natal" descreve a profunda religiosidade dos "infelizes" de origem humilde, que rezavam e tomavam um aspecto circunspecto por ocasião da festa, motivados pela "inata reverência pelo grande dia" (DOSTOIÉVSKI, 2003, p. 161).

A festa religiosa, explica Dostoiévski, desempenhava importante função na vida dos presos, pois "inconscientemente sentiam que o feriado os conectava com todo o mundo" (DOSTOIÉVSKI, 2003, p. 161), com mundo exterior ao presídio que celebrava a mesma data (e do qual chegavam diversas doações), lembrando-lhes "que não haviam se tornado por completo uns proscritos, gente morta, pedaços fatiados e, que, embora estivessem no presídio, eram homens. Eles sentiam isto. Isto era visto e compreendido" (DOSTOIÉVSKI, 2003, p. 161).

A lembrança de que "eram homens" consistiria, de acordo com o relato de Dostoiévski, em um dos principais fatores motivando o comportamento dos encarcerados - a necessidade de afirmar, por vezes de forma irracional e desesperada, a personalidade. A atitude dos "infelizes" em relação ao dinheiro é um dos exemplos através dos quais o autor demonstra que o que motiva o comportamento humano nem sempre possui fundo racional ou objetivo prático imediato e óbvio. Para arranjá-lo, os companheiros de prisão recorriam a artimanhas diversas e aos expedientes mais complexos e arriscados, como, por exemplo, ao contrabando de bebida. Enquanto o fornecedor, fora da cadeia, lucrava, os contrabandistas se expunham a todos os riscos que a atividade proibida, embora tolerada, implicava. Como nos explica Dostoiévski, o capital único de que esses homens dispunham eram as próprias costas (DOSTOIÉVSKI, 2003, p. 83), dilaceradas por vergastadas. O dinheiro conseguido sempre com dificuldade - ou com bastante criatividade - era gasto, não obstante, da maneira mais irrefletida e inconsequente, "de forma leviana, infantil" (DOSTOIÉVSKI, 2003, p. 117).

Uma questão infinitamente maior que a satisfação das necessidades materiais determinava o desejo dos presos por dinheiro: "a liberdade, ou, então, alguma ilusão de liberdade" (DOSTOIÉVSKI, 2003, p. 117), encontrada na possibilidade de dispor e exercitar da própria vontade, infringido regras e entregando-se a prazeres severamente proibidos no presídio, como a bebida e as mulheres; e até obtendo o poder de subornar superiores. Por isso, segundo o autor, "se os presos fossem privados de qualquer possibilidade de ter o próprio dinheiro", ou seja, dessa alternativa de afirmação da vontade e da personalidade dentro do cárcere, "perderiam a sanidade, morreriam como moscas [...] ou se entregariam à vilania inaudita - uns por tristeza, outros para mais depressa serem executados e aniquilados, de alguma forma mudando de sorte" (DOSTOIÉVSKI, 2003, pp. 116-7). O crime, ou a "vilania inaudita" como afirmação da personalidade injustiçada, espezinhada ou sufocada, aparece, nas Memórias, ao fundo do comportamento de muitos dos detentos - tanto em sua trajetória anterior como durante o encarceramento - e se torna tema recorrente nos grandes romances pós siberianos.

Entre a "pessoa viva" e a negação radical de sua condição de sujeito - morte dos direitos civis e políticos, da dignidade física e social, seja na "cova movediça", no "curral de arame" ou na "casa dos mortos"; seja no contexto exterior ao presídio, sempre brutal em relação aos mais humildes, na Rússia oitocentista e no Brasil do início do século - há o substrato da resistência, que, para Dostoiévski, define, a todo o momento, os seus companheiros. 
Resistência que motiva Graciliano a anunciar, diante do Dr. Sardinha, diretor interino da Colônia Correcional, que retribuiria a "hospitalidade que os senhores me deram" escrevendo um livro. Recuando espantado, "de olhos esbugalhados", o diretor, que até então não sabia estar diante de um escritor, teria dito: “- A culpa é desses cavalos que trazem pra cá gente que sabe escrever" (RAMOS, 2015, p. 516). Se Memórias do Cárcere e Recordações da Casa dos mortos se tornaram obras consagradas, muitas outras memórias, de presos anônimos, marginalizados, que "não sabiam escrever", não foram registradas, não chegaram até nós, nunca deixaram a Ilha Grande ou a Sibéria. Recuperar essa história e essa memória é uma necessidade e um desafio históricos que autores como Dostoiévski e Graciliano nos auxiliam a cumprir.

REFERÊNCIAS

ALVES, Fábio César. Armas de papel: Graciliano Ramos, as Memórias do Cárcere e o Partido Comunista Brasileiro. São Paulo: Ed. 34, 2016.

BOSI, Alfredo. "A escrita do testemunho em Memórias do Cárcere". Estudos Avançados. São Paulo, vol. 9, n. 23, 1995, p. 309-322.

AGAMBEN, Giorgio. Homo sacer: o poder soberano e a vida nua I. Belo Horizonte: UFMG, 2010.

DOSTOIÉVSKI, Fiódor. Sobranie sotchinenii v dieviti tomakh. Tomo II. Moscou: ACT, 2003.

FRANK, Joseph. Dostoiévski: os efeitos da libertação (1860 a 1865). São Paulo, EDUSP, 2002 .

RAMOS, Graciliano. Memórias do cárcere. São Paulo: Ed. Record, 2015

SANTOS, Myrian Sepúlveda dos. Os porões da República. A barbárie nas prisões da Ilha Grande: 1884-1945. Rio de Janeiro: Garamond, 2009. 
